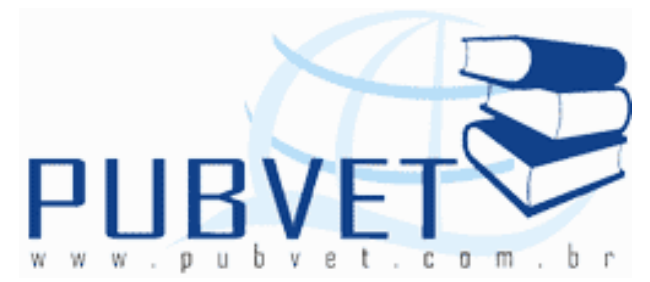

PUBVET, Publicações em Medicina Veterinária e Zootecnia.

\title{
Prolapso e ruptura de útero gravídico em cadela: relato de caso
}

Tereza Cristina Martins da Silva Marinho우 ${ }^{1}$ Camila Pinho Balthazar da Silveira ${ }^{1}$;

Ana Raquel de Araújo Ferreira ${ }^{1}$; Walnilson Mota da Silva²; Camila Paes Bürger $^{3}$; Leandro Ziemer Carneiro ${ }^{1}$; Arianne Pontes Oriá ${ }^{4}$; João Moreira da Costa Neto ${ }^{4 *}$

${ }^{1}$ Médico(a) Veterinario(a) - Pós-graduandos Curso de Especialização sobre a Forma de Residência em Medicina Veterinária - EMVZ/UFBA.

${ }^{2}$ Médico Veterinário - Mestrando - Programa de Pós-graduação em Ciência Animal nos Trópicos - EMVZ/UFBA.

${ }^{3}$ Médica Veterinária - Doutoranda - Programa de Pós-graduação em Cirurgia Veterinária - FCAVJ - UNESP.

${ }^{4}$ Médico(a) Veterinário(a) - Professor(a) Dr.(a).- Departamento da Patologia e Clínicas - EMVZ/UFBA.

* Autor para correspondência jmcn@ufba.br

\section{Resumo}

O prolapso uterino é uma emergência de rara ocorrência em cães. Suas causas são desconhecidas, no entanto, idade, relaxamento da musculatura pélvica, lesões no canal do parto, distocia e atonia uterina podem ser fatores desencadeantes. Seu diagnóstico é baseado na anamnese, achados do exame físico, radiografia, ultrassonografia e vaginoscopia. O tratamento preconizado incluí desde a redução manual até amputação da massa prolapsada e a 
MARINHO, T.C.M.S. et al. Prolapso e ruptura de útero gravídico em cadela: relato de caso. PUBVET, Londrina, V. 6, N. 10, Ed. 197, Art. 1321, 2012.

realização de uma ovariossalpingohisterectomia. O objetivo deste trabalho é relatar a ocorrência de prolapso parcial de útero gravídico em cadela. O animal apresentava histórico de parto laborioso e presença de massa avermelhada protrusa a partir do canal vaginal. Após tratamento de suporte para estabilização do paciente, realizou-se tentativa de redução manual, que mostrou-se infrutífera, sendo então indicada a laparotomia exploratória seguida de ovariosalpingohisterectomia, que resultou na correção do prolapso parcial e ruptura uterina existente, favorecendo o prognóstico com plena recuperação do animal.

Palavras-chave: prolapso parcial uterino, ovariosalpingohisterectomia, ruptura uterina.

\title{
Prolapse and Rupture of the gravid uterus in a dog: case report
}

\begin{abstract}
The uterine prolapse is an emergency rare in dogs. Among the factors that can determine this alteration we can mention the age, primiparas, forced traction, lesions in the birth canal, dystocia and uterine atony. The diagnosis is determined by the anamnesis, physical examination, radiography, ultrasonography and vaginoscopy and; the treatment include manual reduction, prolapsed mass amputation and ovariosalpingohisterectomy. The objective of this study was to report the occurrence of partial prolapse of the gravid uterus in a bitch. The animal had a history of arduous labor and the presence of reddish mass protruding from the vaginal canal. Treatments were imposed to stabilize the support frame and held on attempted manual reduction with the aid of epidural anesthesia. After exploratory laparotomy and subsequent ovariosalpingohisterectomy, this resulted in a correction of the partial prolapse and uterine rupture, giving a favorable prognosis and with full recovery of the animal.
\end{abstract}


MARINHO, T.C.M.S. et al. Prolapso e ruptura de útero gravídico em cadela: relato de caso.

PUBVET, Londrina, V. 6, N. 10, Ed. 197, Art. 1321, 2012.

Keywords: partial uterine prolapse, ovariesalpingohistectomy, uterine rupture.

\section{INTRODUÇÃO}

O prolapso uterino é a eversão e protrusão de uma porção do útero pela cérvix, quando a mesma se encontra dilatada, para dentro da vagina durante ou próximo ao parto (FOSSUM, 2008 \& MOSTACHIO et al., 2008). É uma emergência de ocorrência rara em cães e gatos (PARREIRA, 2007; SLATER, 2007 \& MOSTACHIO et al., 2008) e segundo Costa (2010) é mais comumente observada em gatas, não havendo predisposição etária conhecida.

O acometimento de um ou ambos os cornos uterinos podem ser observados, podendo acometer fêmeas primíparas ou multíparas (COSTA, 2003; MOSTACHIO et al., 2008). A média de idade é de dois anos, podendo ser observados, casos em cadelas com idade entre sete meses a 16 anos (CARUSO, 2005). Diversos fatores podem estar associados a essa patologia, como predisposição hereditária, idade, fetos enfisematosos, lesões de canal do parto, hiperestrogenismo (COSTA, 2003), relaxamento da musculatura pélvica e perineal (COSTA, 2010), atonia uterina, separação incompleta das membranas placentárias, flacidez mesovariana, tenesmo (ZYURTLU, 2005), separação forçada do macho durante o coito, discrepância de tamanho entre os animais reprodutores e contrações uterinas excessivas (NÖTHLING, 2002, CARUSO, 2005, ALAN, 2007 \& MOSTACHIO et al., 2008).

A eversão ou protrusão uterina pode ser completa ou parcial. No primeiro caso, observa-se a presença de ambos os cornos uterinos e corpo do útero evertidos através da vulva, enquanto no parcial, um corno e/ou corpo uterino podem estar evertidos no lúmen vaginal (MOSTACHIO et al., 2008). O tecido evertido tem aspecto rugoso, podendo apresentar-se edemaciado e congesto, evoluir para isquemia, e a depender do tempo de exposição, apresentar também infecção e necrose (FOSSUM, 2008 \& MOSTACHIO et al., 2008). O 
MARINHO, T.C.M.S. et al. Prolapso e ruptura de útero gravídico em cadela: relato de caso. PUBVET, Londrina, V. 6, N. 10, Ed. 197, Art. 1321, 2012.

útero pode estar hemorrágico, ulcerado e coberto por sujidades, pêlos, fezes, ou membranas placentárias (SLATER, 2007).

As complicações que podem acompanhar essa afecção incluem desidratação, obstrução uretral pela compressão da uretra, tenesmo, infertilidade, ruptura dos vasos uterinos, em consequência da laceração do ligamento largo e hemorragia da artéria uterina, podendo levar a hipotensão, choque hipovolêmico e morte (COSTA et al. 2003; TILLEY \& SMITH, 2003, FOSSUM, 2008 \& MOSTACHIO, 2008).

O diagnóstico do prolapso uterino completo é direto e baseia-se na anamnese, sinais clínicos e confirmado pelo exame físico e citologia vaginal (COSTA et al., 2003 \& MOSTACHIO et al., 2008). Nos casos de prolapso parcial, deve ser realizada vaginoscopia e exame digital da vagina, com palpação da massa prolapsada (FOSSUM, 2008 \& COSTA, 2010). As fêmeas podem encontrar-se clinicamente estáveis ou apresentar sinais de inquietação, postura anormal, dor, inchaço perineal, disúria e desequilíbrios metabólicos intensos. Neste último caso recomenda-se tratar os distúrbios presentes antes de se realizar a correção do prolapso (COSTA, 2003, FOSSUM, 2008 \& COSTA, 2010).

Laboratorialmente, não se registram alterações específicas, podendo haver anemia nos casos nos quais há hemorragia e leucocitose na presença de infecção (FOSSUM, 2008 \& COSTA, 2010).

Os diagnósticos diferenciais a considerar são o prolapso/hiperplasia vaginal, tumor vaginal e torção uterina (FOSSUM, 2008, MOSTACHIO, 2008 \& COSTA, 2010).

O tratamento do prolapso uterino visa retornar o útero à posição anatômica e prevenir infecção ou desvitalização do tecido. Vários métodos são descritos na literatura, incluindo redução manual através de palpação abdominal ou laparotomia, seguida ou não de ováriosalpingohisterectomia, e excisão do tecido evertido com ligadura dos vasos uterinos e ovarianos. A ressecção cirúrgica é preconizada nos casos em que os tratamentos instituídos 
MARINHO, T.C.M.S. et al. Prolapso e ruptura de útero gravídico em cadela: relato de caso. PUBVET, Londrina, V. 6, N. 10, Ed. 197, Art. 1321, 2012.

falharem ou nos casos em que envolvam complicações locais, como hemorragia, infecção e necrose (MOSTACHIO et al., 2008).

Inicialmente, preconiza lubrificar e proteger os tecidos expostos, concomitantemente com a instituição de tratamento de suporte (COSTA, 2010). Os pacientes em choque devem ser operados assim que estiverem estabilizados clinicamente e ser previamente tratados com fluidoterapia, fazer a correção dos desequilíbrios ácido-básicos e eletrolíticos. Antibióticos profiláticos são indicados quando o prolapso estiver contaminado ou traumatizado. Os pêlos do abdome e períneo devem ser tricotomizados e as regiões preparadas para a cirurgia (FOSSUM, 2008).

Se o tecido uterino estiver relativamente saudável e sem a presença de fetos, indica-se a redução do prolapso, após a estabilização do animal. Primeiramente, deve-se tentar a redução manual, realizado sob anestesia geral ou local com bloqueio epidural tanto em cães quanto gatos (FOSSUM, 2008 \& COSTA, 2010). Após o animal ser tranqüilizado ou anestesiado, o tecido evertido é submetido à limpeza com solução salina (SLATER, 2007) ou solução anti-séptica diluída (MOSTACHIO, 2008). A recolocação uterina é feita através da aplicação de pressão externa, associada à instilação de soro fisiológico estéril. Em caso de edema dos tecidos protrusos, a sua lavagem com soluções hiperosmóticas, como dextrose a $50 \%$, pode ajudar a diminuir a edemaciação (COSTA, 2010). Se não for possível a redução externa do prolapso a episiotomia pode proporcionar exposição adicional, facilitando a redução do útero prolapsado (PINTO FILHO, 2002).

Após esta abordagem inicial, a laparotomia pode ser considerada para verificar se o útero está corretamente posicionado e se existe integridade da vasculatura uterina. Assim como nos casos em que a redução manual não foi possível, é necessário recorrer à cirurgia. Uma vez reposicionado o útero, deve-se administrar ocitocina (5 a 10 UI IM), para promover a sua involução (COSTA, 2010).

Se a redução uterina não for possível devido ao edema ou necrose, pode ser necessário a amputação do tecido uterino exteriorizado antes da redução 
MARINHO, T.C.M.S. et al. Prolapso e ruptura de útero gravídico em cadela: relato de caso. PUBVET, Londrina, V. 6, N. 10, Ed. 197, Art. 1321, 2012.

desse (ZYURTLU, 2005 \& COSTA, 2010). Para esse procedimento realiza-se uma incisão na porção cranial do corpo uterino, próximo a vulva. As extremidades craniais dos cornos uterinos ficam visíveis (SLATER, 2007). A uretra deve ser sondada para prevenir a ocorrência de trauma (COSTA, 2010), havendo necessidade de anestesia geral ou de anestesia regional epidural (SLATER, 2007). Após a recessão do segmento necrótico, o tecido restante é reduzido manualmente e a laparotomia deve ser realizada para permitir a observação das vísceras e completar a OSH. A castração deve ser realizada sempre que se verifique comprometimento da viabilidade tecidual uterina, ruptura vascular ou se não pretende um cruzamento posterior da fêmea (CARUSO, 2005 \& COSTA, 2010). A ruptura do útero gravídico é rara, mas pode ocorrer durante o parto e os fetos serem eliminados para a cavidade abdominal, podendo vir a óbito e ocasionar peritonite, confirmando assim a realização da ovariosalpingohisterectomia completa (BOJRAB, 1996).

O prognóstico depende do grau e tempo de evolução da afecção. Após a OSH torna-se excelente, quando é possível o controle do choque e hemorragia no pré-operatório, exceto quando há envolvimento e comprometimento da uretra. A agilidade da intervenção é fundamental para um prognóstico positivo (COSTA et al., 2003; COSTA, 2010), como também a estabilização do quadro no pré-operatório. A OSH é o método eficiente e definitivo para cura e prevenção do prolapso uterino (COSTA, 2003) e tem também como outras funções evitar anomalias, prevenção e tratamento de piometra, metrite, neoplasias ovarianas, uterinas ou vaginais, cistos, traumatismos, torção uterina e subinvolução de locais placentários (SOUZA et al., 2010).

Assim, objetivo deste trabalho foi relatar a condição clínico-cirúrgica de uma cadela que apresentava proplapso uterino associado à ruptura desse órgão. 
MARINHO, T.C.M.S. et al. Prolapso e ruptura de útero gravídico em cadela: relato de caso.

PUBVET, Londrina, V. 6, N. 10, Ed. 197, Art. 1321, 2012.

\section{RELATO DE CASO}

Uma cadela, sem raça definida, de sete meses de idade foi atendida no Hospital Veterinário Renato Medeiros Neto da Universidade Federal da Bahia (UFBA), com histórico de parto laborioso e presença de massa avermelhada protrusa pelo canal vaginal. Segundo a proprietária, a gestação da cadela primípara, criada em sistema semi-domiciliar só foi observada por volta dos 40 dias. Iniciou trabalho de parto 24 horas antes do atendimento, tendo neste período parido seis filhotes natimortos com períodos variáveis entre os partos e com muita dificuldade. Relatou ainda que desde o início do processo, observou aumento de volume na região vulvar, caracterizada por uma massa avermelhada que após o nascimento do último filhote aumentou consideravelmente de tamanho.

Ao exame clínico, o animal apresentava apatia, dispnéia, escore corporal 2 (1 a 5), desidratação leve, hipotermia, taquicardia, aumento de volume abdominal e presença de tecido de coloração vermelho escura, contiguo ao canal vaginal, de aproximadamente 15 centímetros de comprimento e variáveis graus de diâmetro com presença de sujidades. À palpação abdominal evidenciou-se significativa tensão e presença de aumento de volume intraabdominal, de formato alongado e localizado na região abdominal umbilical e púbica.

Amostras de sangue foram coletadas para hemograma e análise bioquímica e instituiu-se reposição hidroeletrolítica com infusão de ringer lactato (10 ml/kg/hora) e terapia antimicrobiana a base de cefalotina na dose de $30 \mathrm{mg} / \mathrm{kg} / \mathrm{IV}$. Ato contínuo procedeu-se limpeza da região perineal através de ducha morna e emprego de sabão neutro. $O$ tecido protruso foi irrigado com solução aquosa de clorexidina a $0,2 \%$ e analisado minuciosamente, evidenciando-se prolapso parcial de útero com edema e congestão em parte do corpo uterino e corno esquerdo. Este último em parcial inversão de sua parede, com exposição de seu endométrio e zona placentária e manutenção de porção oclusa com presença de feto (Figura 1). 


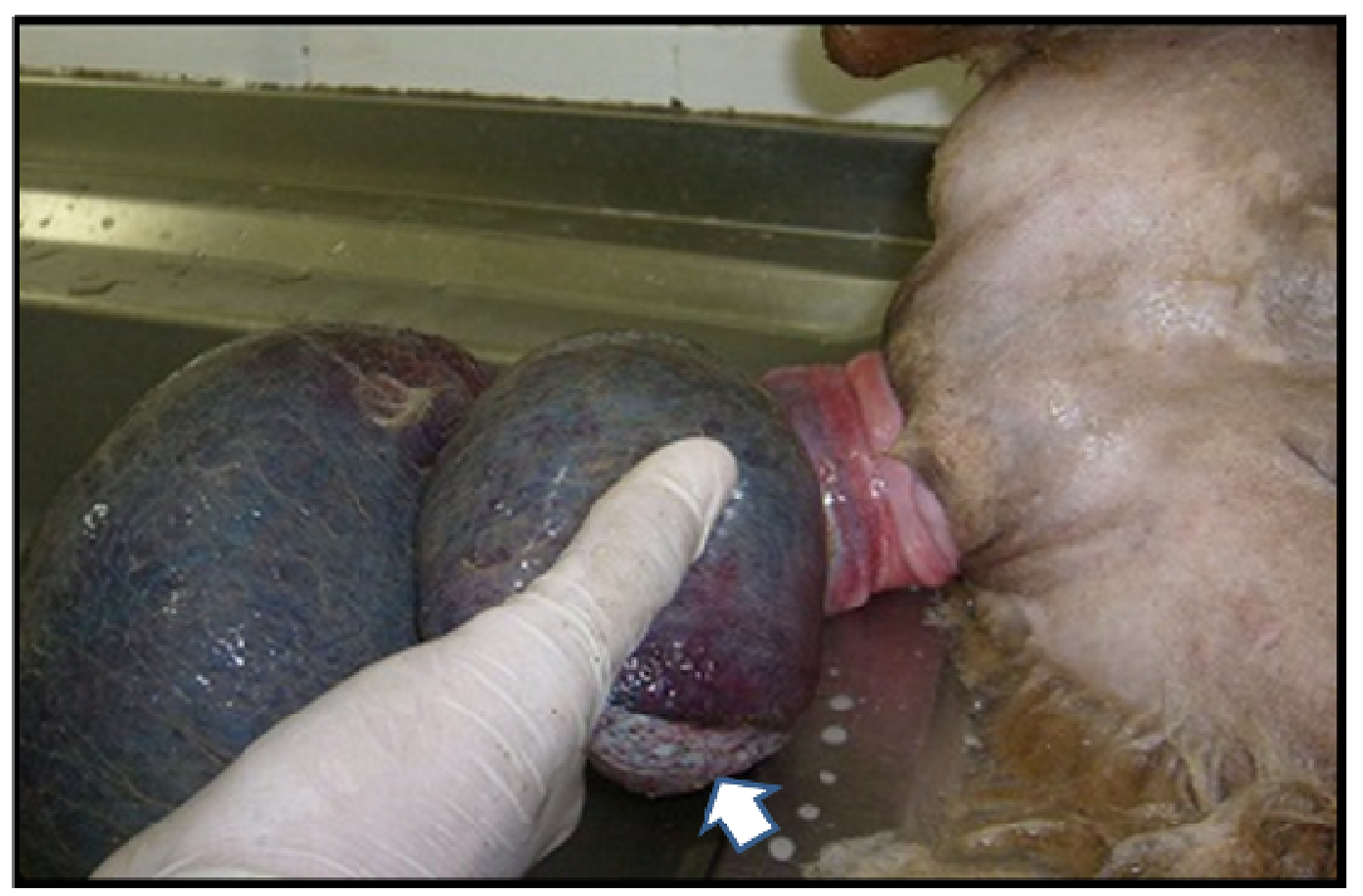

Figura 1: Imagem fotográfica de cadela SRD, com sete meses de idade, apresentando prolapso parcial de útero, com identificação de parte do corpo uterino e um de seus cornos. O corno uterino apresenta-se em inversão da parede, com exposição do endométrio e zona placentária (seta) e manutenção de porção oclusa com presença de feto. Fonte: Arquivo Pessoal

O hemograma revelou anemia normocítica normocrômica e leucocitose. A fosfatase alcalina foi o único parâmetro bioquímico alterado (426U/L). Todos os demais resultados estavam dentro dos valores de referencia para cães. Buscando avaliar possível comprometimento do sistema urinário foi preconizada a sondagem vesical que foi possível e mantida durante todo perioperatório. Logo após, optou-se então pelo procedimento cirúrgico de laparotomia exploratória associada à histerectomia parcial por via vaginal, incluindo-se no período pré-operatório medidas para minimizar o edema e a congestão da porção prolapsada, sendo empregado uso de compressas frias associado ao uso de açúcar granulado (Figura 2). 


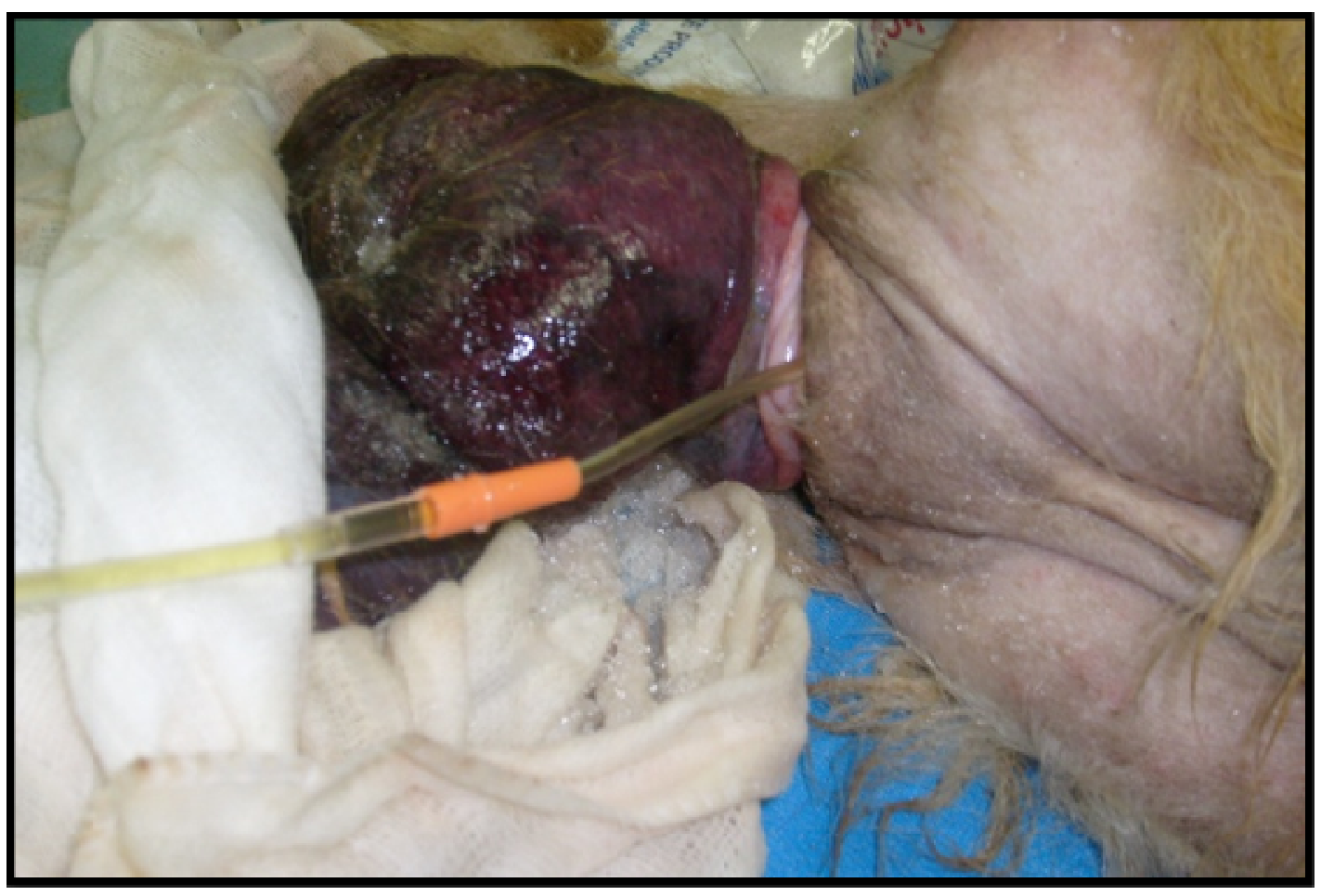

Figura 2: Imagem fotográfica ilustrando manejo do prolapso parcial de útero em cadela SRD de sete meses, empregando-se compressa de solução fisiológica fria e açúcar, além da sondagem uretral. Fonte: Arquivo Pessoal.

A terapêutica clínico-cirúrgica incluiu estabilização prévia do paciente, manutenção da sondagem vesical e a terapia anti-inflamatória 60 minutos antes do procedimento cirúrgico à base de meloxicam $(0,1 \mathrm{mg} / \mathrm{kg} \mathrm{IM})$. O protocolo anestésico compreendeu a associação de cloridrato de acepromazina $(0,05 \mathrm{mg} / \mathrm{kg})$ e cloridrato de tramadol $(2 \mathrm{mg} / \mathrm{kg})$, por via endovenosa como medicação pré-anestésica, seguido de indução com propofol $(5 \mathrm{mg} / \mathrm{kg})$ e manutenção com isoflurano em circuito semiaberto. Adicionalmente, realizouse bloqueio local epidural com lidocaína $2 \%$ sem vasoconstrictor $(5 \mathrm{mg} / \mathrm{kg}$ ).

O procedimento cirúrgico teve início com a laparotomia exploratória pela linha média, evidenciando-se presença de liquido intra-cavitário, resquícios de placenta e envoltórios fetais, superfície peritoneal rugosa, com debris celulares e depósitos de fibrina. O omento maior apresentava-se congesto, aderido a resquícios teciduais e recobrindo parcialmente o corno uterino direito gravídico, 
MARINHO, T.C.M.S. et al. Prolapso e ruptura de útero gravídico em cadela: relato de caso.

PUBVET, Londrina, V. 6, N. 10, Ed. 197, Art. 1321, 2012.

que se encontrava friável, bastante distendido, com áreas de congestão e isquemia, contiguo a porção do corpo uterino insinuado pelo canal pélvico (Figura 3). Evidenciou-se lesão lacerante na porção médio ventral do corno, com exposição de porção placentária e presença de dois fetos mortos. 0 complexo arteriovenoso ovariano (CAVO) apesar de distendido mantinha sua integridade, porém o ligamento suspensório e porções do ligamento largo do útero apresentavam-se parcialmente rompidos.

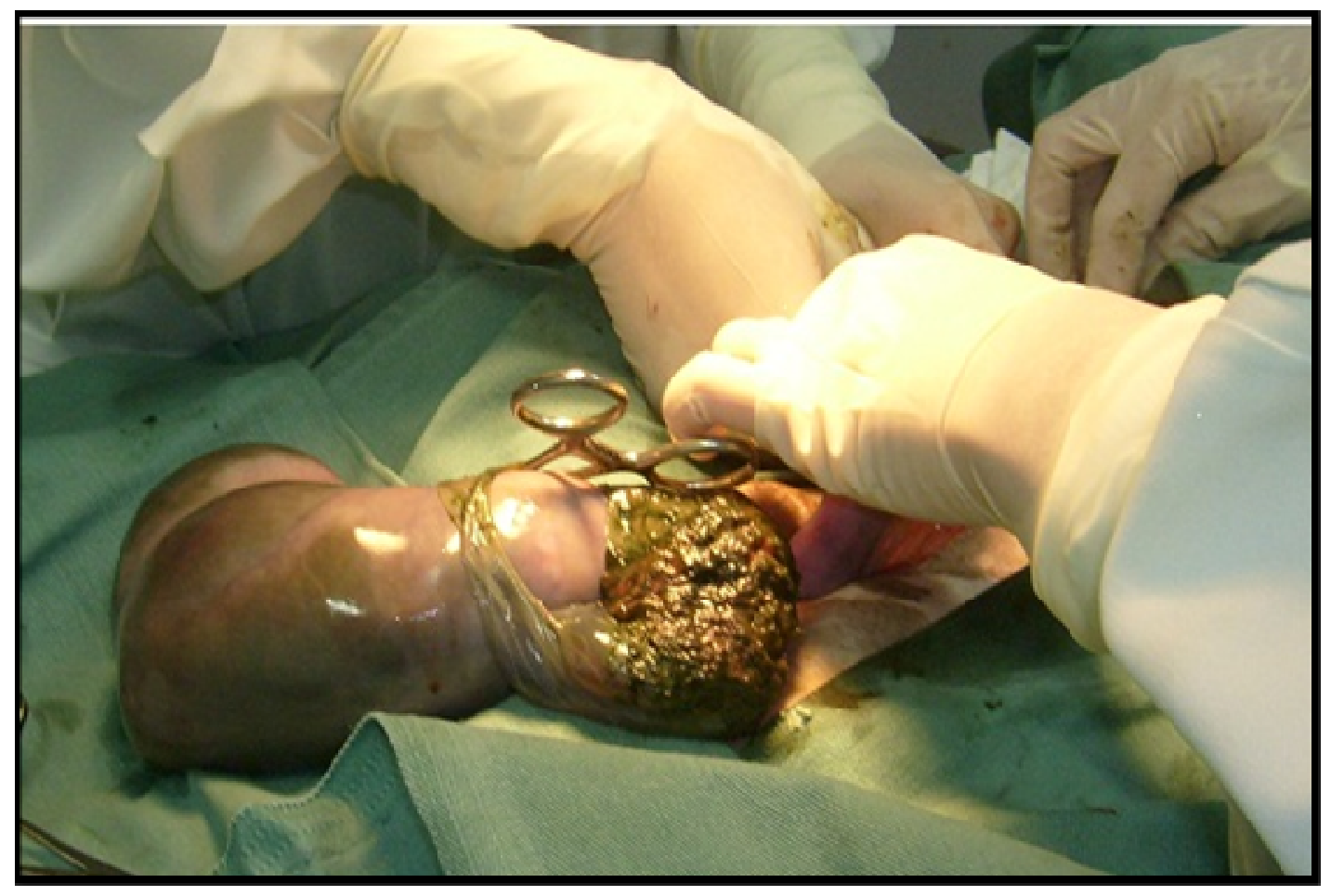

Figura 3: Imagem fotográfica ilustrando transoperatório de laparotomia exploratória evidenciando corno uterino direito gravídico com alterações de serosa e lesão lacerante de parede e exposição de restos placentários. Fonte: Arquivo Pessoal.

Observou-se ainda corno uterino contralateral, totalmente insinuado através do corpo do útero e projetado para o exterior pelo canal vaginal. Ruptura total do CAVO, com presença de coágulos e hemorragia em sua inserção. Ligamento largo e suspensório igualmente rompido. As demais vísceras abdominais não apresentavam lesão. 
MARINHO, T.C.M.S. et al. Prolapso e ruptura de útero gravídico em cadela: relato de caso. PUBVET, Londrina, V. 6, N. 10, Ed. 197, Art. 1321, 2012.

Inicialmente o líquido intra-cavitário foi drenado com auxílio de aspirador cirúrgico e em seguida promoveu-se o pinçamento e obliteração de resquícios do CAVO direito e do CAVO esquerdo empregando-se ligadura simples com fio mononáilon 2-0. O corno uterino esquerdo sofreu retroflexão e foi disposto sobre os panos de campo acessórios e protegido por compressas úmidas. Ato contínuo procedeu-se a histerectomia parcial por via vaginal. Inicialmente, dois pontos de reparo foram confeccionados, dispostos lateralmente à porção protusa do corpo do útero, em seguida a amputação do tecido protruso foi realizada mediante incisão transversal com bisturi tendo-se como referencias os pontos de reparo e o meato urinário, previamente identificado pela sondagem vesical.

Pela via abdominal/pélvica, foi inserida através do corpo uterino insinuado, uma pinça hemostática de Rochester Penn e em sua extremidade foram fixados os cabos dos pontos de reparo. A pinça foi tracionada, auxiliando a reintrodução da porção do corpo do útero protruso. Uma vez na cavidade abdominal, também com auxílio de uma pinça hemostática de Rochester Penn, o coto uterino foi transversalmente pinçado entre o fundo do vestíbulo vaginal e a cérvix. Porções do corpo e corno uterino esquerdo foram retirados do campo operatório. As artérias e veias uterinas esquerda e direita foram obliteradas através de ligadura sob tecido, empregando-se fio de mononáilon 2-0. A oclusão do corpo do útero foi realizada através de transfixação simples associada a sutura de Parker-ker, com mononáilon 2-0. A cavidade peritoneal foi lavada, empregando-se solução fisiológica aquecida ( $36^{\circ} \mathrm{C}$ ), empregando drenagem ativa com auxílio de aspirador cirúrgico. Ato contínuo, omentopexia foi realizada sobre o coto uterino. A síntese da cavidade abdominal, subcutâneo e pele foram realizados de forma rotineira. 
MARINHO, T.C.M.S. et al. Prolapso e ruptura de útero gravídico em cadela: relato de caso.

PUBVET, Londrina, V. 6, N. 10, Ed. 197, Art. 1321, 2012.

\section{DISCUSSÃO E CONCLUSÃO}

O prolapso uterino é uma emergência que ocorre raramente em cães e gatos como descrito por Mostachio e colaboradores (2008). Embora as causas ainda sejam desconhecidas, é consenso que 0 parto distócico é frequentemente implicado como fator predisponente.

De acordo com Luz et al. (2005) vários fatores maternos e fetais podem contribuir para a distocia. A paciente em questão apresentava várias características compatíveis para essa patologia. Era animal primíparo, jovem, mal nutrida, teve cobertura não assistida provavelmente com animais de maior porte. Adicionalmente, os fetos, apesar de bem posicionados eram relativamente grandes para o porte da cadela.

Também baseado no histórico do animal pode-se atribuir a distocia ocorrida, independentemente de sua origem (materna ou fetal) à causa primária do prolapso, corroborando os achados de Özyurtlu \& Kaya (2005) que afirmam que o excesso de contrações uterinas e o relaxamento dos ligamentos e musculatura pélvica ocorridas durante o parto como fatores predisponentes para o prolapso uterino. Paralelamente, os aspectos macroscópicos evidenciados no corno uterino rompido e o início de peritonite demonstraram a agudicidade do quadro e a assertiva de que a distocia e consequente ruptura ocorreram primariamente ao prolapso.

Os sinais clínicos evidenciados na paciente, sugestivos de início de síndrome choque decorreram das alterações hemodinâmicas desencadeadas pela distocia, pelo estado nutricional e pelo longo período de parto e não em decorrência do prolapso, uma vez que o período entre o desencadeamento do prolapso e o atendimento foi menor que seis horas, contrapondo as afirmações de Mostachio et al. (2008) os quais afirmaram que animais atendidos imediatamente após a ocorrência do prolapso encontravam-se saudáveis.

O diagnóstico por imagem é um método adequado nesses casos, pois forneceria informações adicionais necessárias ao planejamento cirúrgico. No entanto, não foi realizado em virtude da desprivilegiada condição financeira do 
MARINHO, T.C.M.S. et al. Prolapso e ruptura de útero gravídico em cadela: relato de caso. PUBVET, Londrina, V. 6, N. 10, Ed. 197, Art. 1321, 2012.

proprietário. Neste caso em especial mostraria as alterações intracavitárias e presença de útero gravídico, justificando a posterior conduta cirúrgica.

A tentativa de redução manual do prolapso uterino é indicada como Fossum (2008) e Mostachio et al. (2008) preconizaram. Porém em virtude dos achados intra-abdominais e da necessidade de laparotomia exploratória, medidas terapêuticas foram tomadas apenas para minimizar o edema e facilitar a histerectomia por via vaginal, conforme cita Slater (2007) e Costa et al. (2010). Seguindo ainda as recomendações de Costa (2010) foi realizada a sondagem vesical para evitar trauma acidental quando da histerectomia parcial por via vaginal.

A laparotomia exploratória além de permitir a verificação da integridade da vasculatura uterina, possibilitou a minuciosa abordagem da cavidade abdominal e pélvica. Por fim, propiciou as manobras cirúrgicas adequadas para a realização da exérese dos cornos e corpo uterino protrusos ou não.

A lavagem da cavidade peritoneal foi empregada para minimizar os efeitos decorrentes do derrame intracavitário e auxiliar na correção da peritonite instalada. De acordo com Torres et al. (1999) este procedimento dilui as enzimas que destroem os antibióticos e digerem os tecidos e retira o material estranho tal como fezes, secreção gastrointestinal, urina, bile, sangue, pus e fibrina. As substâncias tóxicas derivadas das bactérias ou liberadas pela destruição celular são removidas pela irrigação peritoneal. A lavagem peritoneal, quando realizada com solução salina balanceada restaura o metabolismo normal mais rapidamente, possibilitando a correção do desequilíbrio ácido-base e hidroeletrolítico.

Considerando ainda a peritonite instalada, confirmada pela leucocitoce, todas as manobras relativas à síntese e hemostasia foram realizadas empregando-se fio inabsorvível monofilamentar como o fio de náilon, ao invés do uso de fios absorvíveis multifilamentado rotineiramente empregados na cirurgia convencional. De acordo com Ribeiro e Graziano (2003), os fios multifilamentados, por apresentarem maior capacidade de aderência bacteriana contribuem para o aumento das taxas de infecção pós-operatória. 
MARINHO, T.C.M.S. et al. Prolapso e ruptura de útero gravídico em cadela: relato de caso. PUBVET, Londrina, V. 6, N. 10, Ed. 197, Art. 1321, 2012.

A histerectomia por via vaginal com redução do coto restante foi preconizada em decorrência da impossibilidade de redução devido à presença de feto no corpo protruso. De acordo com Mostachio et al. (2008) esta manobra cirúrgica é preconizada nos casos em que ocorrem complicações locais, como no caso em questão. A manobra cirúrgica realizada para redução do coto uterino, empregando pontos de reparo e pinça hemostática de Rochester Penn, mostrou-se adequada e eficaz. Para evitar traumatismo iatrogênico, segundo Okkens (2001) é importante sondar a uretra. A omentopexia realizada sobre o coto uterino, preconizada por Costa Neto et al. (2009), foi realizada para minimizar os riscos de aderência, ao tempo que substituiu a fixação do coto ao peritônio, preconizado por Nak et al. (2008).

A conduta emergencial é imprescindível para um prognóstico favorável, com condutas preconizadas por Costa et al. (2003) que liquidem alterações hemodinâmicas incompatíveis com a vida. No caso em questão o prognóstico foi favorável, pois a intervenção clínica foi imediata. O animal apresentou melhora de forma gradativa e significativa após estabilização do quadro clínico e realização do procedimento cirúrgico.

Assim, conclui-se que a realização de condutas emergenciais como instituição de tratamentos de suporte e a realização de ovariossalpingohisterectomia mostraram-se métodos eficientes e definitivos para cura e prevenção do prolapso uterino e ruptura uterina.

\section{REFERÊNCIAS}

ALAN M.; CETINA Y.; SENDAGA S.; ESKIA F. True vaginal prolapse in a bitch. Animal Reproduction Science, v.100, n.3-4, p.411-414, 2007.

BOJRAB, M. J. Moléstias do Útero. Mecanismos da Moléstia na Cirurgia dos Pequenos Animais. Segunda edição, Editora Manole, 1996, p. 665 - 669.

CARUSO J. L. Etude clinique du prolapsus vaginal chez la chienne. Ecole Nationale Veterinaire D'Alfort. la Faculte de Medecine de Creteil. Paris. Année 2005.

COSTA, J. L. O.; PENA, S. B.; BARDELA, G. T. e FRANCESCHETTI, F. G. Prolapso Uterino Relato de Caso. Anais da III SEPAVET - Semana de Patologia Veterinária - E do II Simpósio de Patologia, 2003. 
COSTA NETO, J. M; TEIXEIRA, E. M.; FERREIRA FILHO, E. M.; TORÍBio, J.M. M.L.; ALMEIDA FILHO, C. H. R.; MORAES,V. J. Braçadeiras de náilon para hemostasiapreventiva na ovariosalpingohisterectomia em gatas. Revista Brasileira de Saúde e Produção Animal, v.10, n.3, p 615.-624, 2009.

COSTA, T. I. R. Urgências Reprodutivas na Cadela. Dissertação de Mestrado Integrado em Medicina Veterinária. Universidade Técnica de Lisboa. Faculdade de Medicina Veterinária, 2010.

FOSSUM, T. W. Prolapso Uterino. Cirurgia de Pequenos animais. Terceira Edição.Editora Elsevier, 2008 p.745 - 747.

LUZ, M. R.; FREITAS, P. M. C.; PEREIRA, E. Z. Gestação e parto em cadelas: fisiologia, diagnóstico de gestação e tratamento das distocias. Revista Brasileira de Reprodução Animal, v.29, n.3/4, p.142-150, 2005.

MOSTACHIO, G.Q.; Vicente, W. R. R.; Cardilli, D. J.; Motheo ,T. F.; Toniollo, G. H. Prolapso Uterino em Gata e Retroflexão Uterina em Cadela. Ciência Animal Brasileira, v. 9, n.3, p.801-805, 2008.

NAK, D. et al. First report of vaginal prolapse in an ovariohysterectomised bitch - a case report. Bull Vet Inst Pulawy. v. 52, p. 397-398, 2008. Disponível em:<http://bulletin.piwet.pulawy.pl/images/stories/pdf/20083/20083397398.pdf>. Acesso em 23 mai 2010.

NÖTHLING JO, UM, KNESLA O., P. E E. IRONSA L. Uterine prolapse with an interesting vascular anomaly in a cheetah: a case report. Department of Production Animal Studies and Department of Paraclinical Sciences, Faculty of Veterinary Science, University of Pretoria, Private Bag X04, Onderstepoort 0110, South Africa. v.58, n.9, p.1705-1712, 2002.

OKKENS, A. C. S. Vaginal edema and vaginal fold prolapse in the bitch, including surgical management. In: Recent Advances in Small Animal Reproduction. CONCANNON P. W. et al. International Veterinary Information Service. Ithaca, New York, USA, 2001. Disponível em: <http://www.ivis.org/advances/Concannon/schaefers/ chapter_frm.asp ?LA=1>. Acesso em 20 mar. 2010.

PARREIRA, IVONETE MARIA. Enciclopédia Biosfera. No03, janeiro - junho 2007, ISSN 1809-0583.

PINTO FILHO, S. T. L.; HENRIQUES, G. B.; DALMOLIN, F. Hiperplasia e Prolapso Vaginal em Cadela - Relato de caso. Revista da Faculdade de Zootecnia,Veterinária e Agronomia. Uruguaiana, v. 9, n. 1, p. 89-94. 2002.

RIBEIRO, A. R.; GRAZIELE, K. U. Os fios de sutura cirúrgica e a enfermeira de centro cirúrgico: critérios de previsão e provisão segundo a natureza das instituições hospitalares. Revista da Escola de Enfermagem. USP. São Paulo, v. 37, n. 4. p. 61-68. 2003.

SLATER, D. Ovário e Útero. Manual de Cirurgia de Pequenos Animais. Terceira Edição. Editora Manole, 2007, v. 2, p.1494-1495.

SOUZA, F. M. de; SANTOS, R. M. B.; LIMA, E. B. de; MIRANDA, M. P. de; ALBUQUERQUE, M. de; FARIAS, M. C. de; RAMOS, R. P.; TAVARES, R. de M.; ARAÚJO, Í. M. de M.; ALMEIDA, E. L. de. Anatomia Topográfica Aplicada a Cirurgia Ováriosalpingohisterectomia (OSH) em Cadela. X Jornada de Ensino, Pesquisa e Extensão - JEPEX 2010 - UFRPE: Recife, 18 a 22 de outubro. 
TORRES, O. J. M.; Peritonite Fecal em Ratos: Eficácia da Lavagem da Cavidade Peritoneal com Solução de Cloreto de Sódio a 0,9\%. Acta Cirúrgica Brasileira - Vol. 14 (2) 1999.

ZYURTLU, N.; KAYA D. Unilateral Uterine Prolapse in a Cat.. Turk J Vet Anim Sci 29. 2005. Turquia, p.941-943. 